\title{
IMPLEMENTASI SUPPORT VECTOR MACHINE UNTUK DETEKSI STRES PADA PENGGUNA E-LEARNING
}

\author{
Fajar Pradana*1, Fitra A. Bachtiar², Muhammad Zulfikarrahman ${ }^{3}$ \\ Email: ${ }^{1}$ fajar.p@ub.ac.id, ${ }^{2}$ fitra.bachtiar@ub.ac.id, ${ }^{1,2,3}$ Jovizulfikar@ @ student.ub.ac.id \\ *Penulis Korespondensi
}

(Naskah masuk: 17 November 2020, diterima untuk diterbitkan: 19 Juli 2021)

\begin{abstract}
Abstrak
Pada masa ini, e-learning cenderung monoton yang hanya digunakan untuk otomasi pekerjaan saja. Pada pengembangan e-learning yang akan datang, e-learning menerapkan lingkungan adaptif agar hasil yang didapatkan dari penggunaan e-learning dapat menjadi lebih optimal. Salah satu strategi agar e-learning menjadi adaptif adalah adaptasi dengan kondisi mental pengguna. Contoh kasus ketika pengguna stres maka sistem elearning yang adaptif akan memberikan materi latihan yang lebih mudah atau memberi notifikasi untuk istirahat. Deteksi stres dapat dilakukan dengan pengolahan data dari sinyal fisiologis, yaitu heart rate. Metode klasifikasi Support Vector Machine diterapkan untuk deteksi stres. Fitur yang digunakan untuk klasifikasi stres adalah fitur yang berasal dari domain Heart Rate Statistical. Pengujian akurasi metode Support Vector Machine terhadap kasus pengguna e-learning mampu menghasilkan akurasi sampai 58,3\% dengan menggunakan 12 sampel data.
\end{abstract}

Kata kunci: support vector machine, heart rate, stres.

\section{IMPLEMENTATION OF SUPPORT VECTOR MACHINE FOR STRESS DETECTION IN E-LEARNING USERS}

\begin{abstract}
This time, e-learning tends to be monotonous which is only for job automation. In future of e-learning development, e-learning will apply adaptive environment so that the result obtained from e-learning can be more optimal. One of the strategies to turn e-learning to be adaptive is adaptation to user's mental condition. By example, when user is stressed then adaptive e-learning system will provide easier exercise or pop notification for break. Stress detection can be achieved by processing data from physiological signal that is heart rate. The Support Vector Machine classification method can be implemented for stress detection. The features that used for stress detection are derived features from Heart Rate Statistical domain. The Support Vector Machine validation testing on case of e-learning users able to provide 58,3\% accuracy by using 12 samples of data.
\end{abstract}

Keywords: support vector machine, heart rate, stress.

\section{PENDAHULUAN}

Pada era digital saat ini, semakin banyak konten yang dapat diakses secara daring seiring dengan berkembangnya teknologi saat ini. Dalam hal kegiatan belajar mengajar, digitalisasi materi pelajaran atau mata kuliah telah banyak dilakukan. Tidak hanya digitalisasi materi, interaksi antara murid dan guru atau mahasiswa dan dosen dapat dilakukan secara virtual yang artinya tidak ada tatap muka secara langsung seakan-akan menghilangkan dimensi ruang sehingga kegiatan belajar mengajar lebih efisien. Penggunaan perangkat digital memang menawarkan kelebihan dalam penggambaran lingkungan digital yang beberapa kasus tidak dapat ditiru dalam lingkungan nyata (Clark \& Mayer, 2011). Lingkungan digital tersebut dapat mendukung terbentuknya lingkungan baru yang dapat disebut E-learning. E-learning adalah instruksi yang disampaikan melalui perangkat digital seperti perangkat komputer atau perangkat seluler yang dimaksudkan untuk mendukung pembelajaran (Clark \& Mayer, 2011).

Pada masa ini, e-learning cenderung monoton dan hanya sebatas menjadi alat bantu untuk mempermudah pekerjaan dengan mengotomatiskan pekerjaan yang biasa dilakukan secara manual. Pada pengembangan e-learning yang akan datang, lingkungan adaptif akan diterapkan agar e-learning dapat beradaptasi dengan pengguna. Salah satu strategi agar e-learning menjadi adaptif adalah adaptasi dengan kondisi mental pengguna. Stres pada pengguna memiliki dampak pada pembentukan 
dan pengambilan ingatan yang berimplikasi bahwa stres dapat mengubah sifat atau kualitas ingatan serta dapat menyebabkan salah tangkap informasi (Vogel \& Schwabe, 2016). Contoh kasus ketika pengguna menemui materi latihan yang cenderung sulit secara terus-menerus dan ada kemungkinan membuat stres pengguna maka sistem e-learning yang adaptif akan memberikan materi latihan yang lebih mudah atau memberi notifikasi untuk istirahat dengan tujuan untuk menekan stres pada pengguna.

Deteksi stres dapat dilakukan dengan pengolahan data dari sinyal fisiologis, yaitu heart rate. Heart rate adalah jumlah detakan jantung pada rentan waktu tertentu dan umumnya diukur dalam satuan beats per minute (bpm). Sriramprakash et al. (2017) menggunakan fitur yang berasal dari domain heart rate untuk klasifikasi stres.

Pada penelitian yang dilakukan oleh Sriramprakash et al. (2017), metode klasifikasi yang digunakan adalah metode Support Vector Machine yang telah dibandingkan dengan metode K-Nearest Neighbor dan telah dibuktikan memiliki akurasi lebih tinggi. SVM membutuhkan komputasi yang jauh lebih kecil dibandingkan dengan NN (Ben Salem and Nasri, 2009). Maka dari itu, penelitian ini mengusung solusi deteksi stres dengan menggunakan Support Vector Machine sebagai metode klasifikasi stres. Penelitian ini diharapkan dapat berkontribusi untuk penerapan lingkungan adaptif pada lingkungan e-learning sehingga hasil pembelajaran menjadi optimal.

\section{METODE PENELITIAN}

Metode penelitian dibuat untuk membantu agar penelitian menjadi terencana dan sistematis. Gambar 1 menunjukan langkah-langkah yang dilakukan pada penelitian ini. Langkah-langkah tersebut meliputi pre-processing data, pengambilan data uji, proses klasifikasi, hasil klasifikasi dan pengujian akurasi.

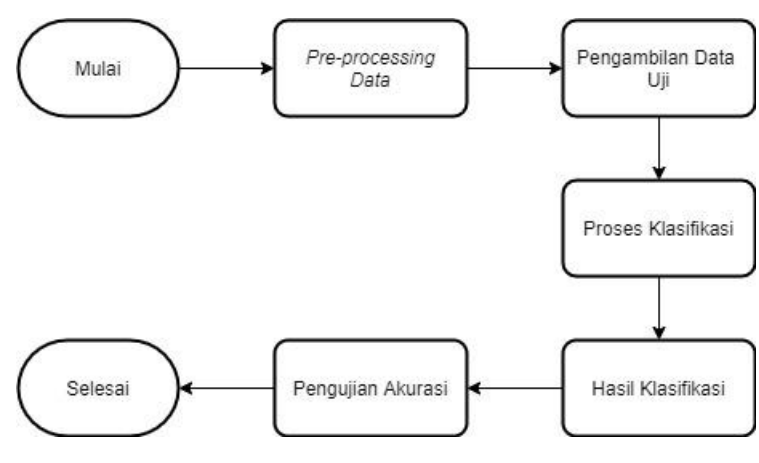

Gambar 1. Metode Penelitian

\subsection{Pre-processing Data}

Tahapan pertama yang dilakukan pada penelitian ini adalah pre-processing data, yaitu mengolah data mentah sebelum digunakan untuk klasifikasi. Proses pre-processing data dilakukan secara manual. Pada penelitian ini, data yang digunakan adalah data yang didapat dari penelitian sebelumnya, yaitu dari Koldijk et al. (2014). Pada penelitian tersebut diambil data heart rate dari beberapa sampel responden yang sedang mengerjakan tugas tertentu untuk beberapa sesi. Pada akhir sesi, tingkat stres responden akan dicatat dengan menanyakan langsung kepada responden mengenai tingkat stres yang dialami responden.

Pada penelitian yang dilakukan oleh Sriramprakash et al. (2017), fitur-fitur yang dapat digunakan untuk klasifikasi stres telah didefinisikan. Pada pengambilan data uji, perangkat yang digunakan pada penelitian ini untuk mendapatkan data heart rate yaitu $\mathrm{Mi}$ Band 2. Dengan menggunakan perangkat tersebut, fitur untuk klasifikasi yang dapat digunakan adalah dari domain Heart Rate Statistical, yaitu Mean Heart Rate, Median Heart Rate, Mean Absolute Deviation Heart Rate dan Standard Deviation Heart Rate.

Data yang didapat dari penelitian Koldijk et al. (2014) yaitu berupa heart rate time-series untuk setiap sesi tugas dan terdapat definisi tingkat stresnya. Data tersebut masih kotor karena ada beberapa data yang hilang. Untuk sesi yang beberapa data heart rate-nya hilang, maka data tersebut diisi dengan merata-rata data heart rate tersebut dengan alasan data tersebut tidak bisa ditebak dengan melihat data lain dan bergantung pada sensor. Terdapat juga beberapa sesi yang tidak ada data sama sekali sehingga harus dihilangkan. Kemudian data time-series yang sudah bersih dapat diolah dengan menggunakan rumus statistik, yaitu mean, median, mean deviasi absolut dan standar deviasi sehingga data yang dibutuhkan untuk klasifikasi telah terpenuhi. Tingkat stres pada data set berupa nilai kontinu antara 0-10. Agar tingkat stres menjadi informatif, maka ditetapkan threshold sebagaimana ditunjukkan oleh Tabel 1.

\begin{tabular}{cc}
\hline Label & Range \\
\hline Tidak Stres & 0 \\
Stres Ringan & $0,1-3,0$ \\
Stres Sedang & $3,1-6,0$ \\
Stres Berat & $6,1-8,0$ \\
Stres Sangat Berat & $8,1-10,0$ \\
\hline
\end{tabular}

\subsection{Pengambilan Data Uji}

Tahapan kedua yang dilakukan pada penelitian ini adalah pengambilan data uji. Data uji didapatkan melalui aplikasi berbasis Android. Gambar 3 merupakan sampel tangkapan layar aplikasi yang telah dikembangkan untuk mengambil data heart rate.

Untuk mendapatkan data heart rate, aplikasi tersebut harus dihubungkan ke sebuah smartwatch terlebih dahulu melalui Bluetooth. Pada penelitian ini, smartwatch yang digunakan adalah Mi Band 2. Aplikasi akan memicu smartwatch untuk menyalakan sensor heart rate secara terus-menerus dan kemudian data heart rate tersebut dikirimkan ke 
aplikasi Android sehingga data heart rate dapat disimpan.

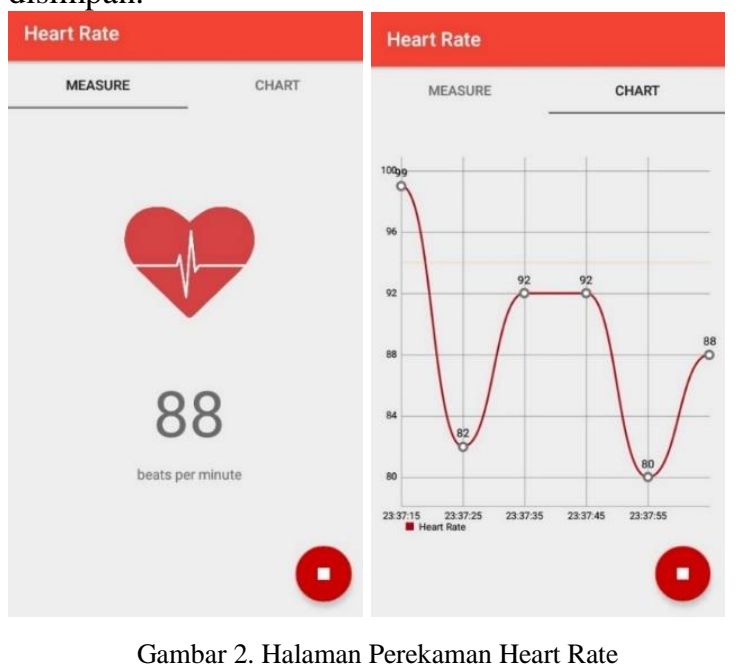

Tabel 2 merupakan contoh data heart rate yang didapat selama 10 menit. Kemudian, data tersebut diekstrak menjadi fitur-fitur yang dapat digunakan dalam klasifikasi. Tabel 3 merupakan hasil nilai fitur yang didapat.

\subsection{Proses Klasifikasi dan Hasil Klasifikasi}

Tahapan ketiga yang dilakukan pada penelitian ini adalah proses klasifikasi dan mengetahui hasil klasifikasi. Dari data uji yang didapat, data tersebut akan melalui proses klasifikasi menggunakan SVM dengan kernel RBF. Pada penelitian ini, nilai Gamma ditetapkan menjadi 0,001. Kemudian, data dimasukkan ke Persamaan 1 untuk setiap jarak dari data uji ke data latih. Hasil klasifikasi dinilai berdasarkan jarak data uji ke data latih terdekat, yaitu hasil perhitungan dengan nilai yang terbesar.

\begin{tabular}{cc} 
& Tabel 2 Contoh Data Heart Rate \\
\hline No & Heart Rate \\
\hline 1 & 80 \\
2 & 83 \\
3 & 79 \\
4 & 90 \\
5 & 74 \\
6 & 46 \\
7 & 71 \\
8 & 68 \\
9 & 74 \\
10 & 70 \\
11 & 83 \\
12 & 72 \\
13 & 77 \\
14 & 82 \\
15 & 80 \\
16 & 41 \\
17 & 56 \\
18 & 82 \\
19 & 79 \\
20 & 68 \\
21 & 62 \\
22 & 80 \\
23 & 47 \\
24 & 75 \\
25 & 74 \\
26 & 51 \\
\hline
\end{tabular}

\begin{tabular}{cc}
\hline No & Heart Rate \\
\hline 27 & 76 \\
28 & 80 \\
29 & 68 \\
30 & 80 \\
31 & 86 \\
32 & 42 \\
33 & 79 \\
34 & 56 \\
35 & 71 \\
36 & 74 \\
37 & 71 \\
38 & 65 \\
39 & 100 \\
40 & 92 \\
41 & 76 \\
42 & 87 \\
43 & 81 \\
44 & 60 \\
45 & 80 \\
46 & 73 \\
47 & 71 \\
48 & 74 \\
& \\
Fitur & Nabel 3 Nilai Fitur \\
\hline Mean HR & 72,6 \\
Median HR HR HR & 74,3 \\
\hline & 12,6 \\
\hline STD \\
\hline
\end{tabular}

Misalkan, nilai fitur telah diketahui seperti Tabel 3 dan titik data latih yang ingin dihitung jaraknya adalah mean $=67,5$, median $=67, \mathrm{MAD}=$ 1,9 dan $\mathrm{STD}=2,4$. Mean, MAD dan STD dapat dihitung dengan menggunakan Persamaan 2, 3 dan 4. Median dihitung dengan menggunakan Persamaan 5 untuk jumlah data ganjil atau Persamaan 6 untuk jumlah data genap. Langkah selanjutnya yang dilakukan adalah menghitung jarak Euclidian dari data uji dan data latih. Perhitungan jarak Euclidian data tersebut ditunjukkan oleh Persamaan 7, Persamaan 8 dan Persamaan 9. Kemudian, nilai jarak Euclidian dan Gamma dimasukkan ke Persamaan 1 sebagaimana ditunjukkan oleh Persamaan 10 dan Persamaan 11. Perhitungan selanjutnya dilakukan untuk setiap titik data latih. Semakin besar nilainya maka semakin dekat kedua titik tersebut.

$$
\begin{aligned}
& \text { mean }=\frac{\sum_{i=1}^{n} x_{i}}{n} \\
& M A D=\frac{\sum_{i=1}^{n}\left|x_{i}-\bar{x}\right|}{n} \\
& S T D=\sqrt{\frac{\sum_{i=1}^{n}(x-\bar{x})^{2}}{n}} \\
& \text { median }=\frac{x_{n+1}}{2} \\
& \text { median }=\frac{x_{\frac{n}{2}+x_{\bar{n}}+1}}{2}
\end{aligned}
$$


||$x-x^{\prime} \|=\sqrt{\begin{array}{c}\left(x_{\text {mean }}-x_{\text {mean }}^{\prime}\right)^{2}+ \\ \left(x_{\text {median }}-x_{\text {median }}^{\prime}\right)^{2}+ \\ \left(x_{\text {mad }}-x_{\text {mad }}^{\prime}\right)^{2}+ \\ \left(x_{\text {std }}-x^{\prime}{ }_{\text {std }}\right)^{2}\end{array}}$

||$x-x^{\prime} \|=\sqrt{\begin{array}{c}(72,6-67,5)^{2}+(74-67)^{2} \\ +(9,3-1,9)^{2}+(12,6-2,4)^{2}\end{array}}$

||$x-x^{\prime}||=233,7$

$k\left(x, x^{\prime}\right)=\exp \left(-0,001 \cdot 233,7^{2}\right)$

$k\left(x, x^{\prime}\right)=0,791580331$

\subsection{Pengujian Akurasi}

Tahap terakhir dari penelitian ini adalah pengujian akurasi. Pengujian akurasi dilakukan dengan membandingkan hasil klasifikasi yang diperoleh dari sistem dengan kondisi real pengguna. Pada penelitian ini, data uji menggunakan 12 data uji yang didapat dari 4 responden.

\section{SUPPORT VECTOR MACHINE}

Support Vector Machine (SVM) merupakan suatu metode klasifikasi yang menggunakan hyperplane sebagai garis pemisah antar kelas. Support Vector Machine (SVM) adalah sebuah metode klasifikasi biner yang dikembangkan oleh Vapnik dan rekan-rekannya di Laboratorium Bell, yang merupakan algoritma lanjutan pada perbaikan yang dilakukan pihak lain (Imaduddin, Zaki, Abidzar T., Hilmy, 201). Ide dari SVM adalah mencari hyperplane yang optimal dan minim eror untuk memisahkan klasifikasi data. Pada metode SVM, data latih tertentu saja yang dapat mempengaruhi peletakan hyperplane sehingga memungkinkan metode SVM mendapatkan akurasi tinggi dengan menggunakan data yang sedikit (Zheng et al., 2015).

SVM mempunyai dua macam kernel, yaitu linier dan non-linier. Kernel linier digunakan untuk klasifikasi data yang dapat dipisahkan dengan garis sedangkan kernel non-linier digunakan untuk klasifikasi data dengan dimensi tinggi. Dalam penerapan awalnya, SVM hanya digunakan untuk klasifikasi data yang dapat dipisahkan dengan garis. Namun, pada saat ini klasifikasi data dimensi tinggi dapat dilakukan dengan menggunakan kernel trik, yaitu kernel non-linier.

Salah satu kernel non-linier dalam SVM adalah Radial Basis Function (RBF). RBF adalah suatu fungsi yang digunakan untuk menghitung jarak antar data berdasarkan jarak Euclidian. Pada penelitian yang dilakukan oleh Sriramprakash et al. (2017), metode klasifikasi SVM dengan kernel RBF dapat menghasilkan akurasi lebih tinggi jika dibandingkan dengan metode klasifikasi K-Nearest Neighbor
(KNN) untuk kasus klasifikasi stres dengan menggunakan data latih dari Koldijk et al. (2014). Persamaan 1 menunjukkan persamaan RBF pada SVM.

$k\left(x, x^{\prime}\right)=\exp \left(-\gamma\left\|x-x^{\prime}\right\|^{2}\right)$

\section{HEART RATE}

Jantung yang dalam bahasa latin dikenal dengan nama Cor merupakan organ tubuh yang memiliki tugas untuk memompa darah melewati pembuluh darah dengan cara kontraksi berirama secara berulang (Shofia, Rahmi amiratus, dkk. 2013). Detak jantung normal merupakan penanda kesehatan pada tubuh baik secara keseluruhan. Heart rate adalah jumlah detakan jantung pada rentan waktu tertentu. Heart rate umumnya dinyatakan dalam jumlah detak jantung dalam satu menit atau biasa disebut satuan beats per minute (BPM). Pada masa ini, sudah banyak alat bantu yang bisa digunakan untuk deteksi heart rate, contohnya adalah smartwatch.

Nilai heart rate dipengaruhi oleh sistem saraf otonom. Hal tersebut dikarenakan sistem saraf otonom mengatur kerja jantung. Sistem saraf otonom dibagi menjadi dua jenis, yaitu saraf simpatik dan saraf parsasimpatik. Saraf-saraf tersebut bekerja secara berlawanan. Misalkan ketika terjadi stres, maka saraf simpatik akan diaktifkan dan saraf parasimpatik akan ditekan sehingga heart rate akan terpengaruh. Heart rate dapat digunakan untuk deteksi stres karena heart rate mempunyai relevansi terhadap respon saraf otonom ketika terdapat stresor.

\section{E-LEARNING ADAPTIF}

E-learning merupakan media pembelajaran yang mengintegrasikan informasi melalui internet (Dhupia, Bhawna, Abdalla Alameen, 2019) Elearning memungkinkan terciptanya lingkungan virtual. Di dalam lingkungan tersebut, murid dan guru atau mahasiswa dan dosen dapat saling berinteraksi. Tidak hanya itu, materi pelajaran atau materi perkuliahan juga dapat diakses secara digital dalam lingkungan tersebut.

Kendala e-learning pada saat ini adalah ketika sistem tersebut tidak mengetahui kondisi pengguna, dalam hal ini adalah kondisi mental pengguna. Dalam kondisi stres, pengguna tidak dapat menyerap informasi dengan baik. Pada lingkungan konvensional, hal tersebut ditekan dengan aksi dari guru atau dosen untuk mencairkan suasana.

E-learning adaptif muncul sebagai solusi untuk meningkatkan kualitas belajar mengajar pada lingkungan virtual. Setiap pengguna e-learning memiliki preferensi yang berbeda terhadap cara belajar (Truon, 2016). Materi pembelajaran adaptif termasuk teks, grafik, audio, video, animasi dan simulasi yang biasa digunakan merancang model 
pembelajaran yang sesuai untuk pelajar (Cannataro, 2013). E-learning adaptif harus mampu mengetahui kondisi stres pengguna sehingga sistem tersebut dapat memberikan umpan balik atau aksi yang tepat terhadap pengguna. Salah satu cara untuk mengetahui kondisi stres pengguna adalah pemantauan sinyal fisiologi pengguna, yaitu heart rate.

\section{HASIL DAN PEMBAHASAN}

Pada penelitian ini dilakukan pengujian akurasi dengan menggunakan 12 data sampel yang didapatkan dari 4 responden yang dipilih dari mahasiswa yang pernah menggunakan e-learning. Setiap responden diberi tugas untuk belajar dengan menggunakan e-learning selama tiga sesi. Kemudian, pada akhir sesi akan ditanyakan bagaimana kondisi stres responden. Tabel 4 menunjukkan hasil klasifikasi yang dihasilkan oleh sistem dan Tabel 5 menunjukkan perbandingan hasil klasifikasi dengan kondisi real responden.

Berdasarkan hasil pengujian, tingkat akurasi yang mampu dihasilkan adalah 58,3\%. Nilai akurasi tersebut dapat dipengaruhi dua hal, yaitu fitur yang digunakan dan tingkat akurasi sensor heart rate dari smartwatch. Karena keterbatasan kemampuan smartwatch, maka fitur yang bisa digunakan adalah hanya dari domain Heart Rate Statistical sehingga fitur-fitur yang lain tidak bisa terpenuhi datanya. Sensor heart rate juga berpotensi mengalami kesalahan yang mengakibatkan data heart rate tidak akurat.

\begin{tabular}{|c|c|c|c|c|c|}
\hline No & Mean & Median & MAD & STD & Hasil \\
\hline 1 & 75,5 & 81 & 13,2 & 15,6 & $\begin{array}{c}\text { Stres } \\
\text { Ringan }\end{array}$ \\
\hline 2 & 71,6 & 72 & 11 & 14,2 & $\begin{array}{l}\text { Stres } \\
\text { Berat }\end{array}$ \\
\hline 3 & 66,7 & 66 & 10 & 12,7 & $\begin{array}{c}\text { Stres } \\
\text { Ringan }\end{array}$ \\
\hline 4 & 67,9 & 67 & 6,6 & 8,6 & $\begin{array}{c}\text { Stres } \\
\text { Ringan }\end{array}$ \\
\hline 5 & 66 & 64 & 9,6 & 12,8 & $\begin{array}{c}\text { Stres } \\
\text { Ringan }\end{array}$ \\
\hline 6 & 69,6 & 69 & 5,9 & 7,8 & $\begin{array}{c}\text { Stres } \\
\text { Ringan }\end{array}$ \\
\hline 7 & 74,1 & 80 & 15,9 & 18,4 & $\begin{array}{c}\text { Stres } \\
\text { Ringan }\end{array}$ \\
\hline 8 & 76,6 & 79 & 11,0 & 13,9 & $\begin{array}{l}\text { Stres } \\
\text { Ringan }\end{array}$ \\
\hline 9 & 74,9 & 80 & 12,3 & 4,3 & $\begin{array}{l}\text { Stres } \\
\text { Sedang }\end{array}$ \\
\hline 10 & 72,6 & 74 & 9,3 & 12,6 & $\begin{array}{c}\text { Stres } \\
\text { Berat }\end{array}$ \\
\hline 11 & 66,1 & 68,0 & 7,7 & 10,5 & $\begin{array}{c}\text { Stres } \\
\text { Ringan }\end{array}$ \\
\hline 12 & 65,9 & 69 & 8,6 & 10,95 & $\begin{array}{c}\text { Stres } \\
\text { Ringan }\end{array}$ \\
\hline
\end{tabular}

\section{KESIMPULAN}

Berdasarkan hasil penelitian yang dilakukan, kesimpulan yang bisa didapatkan adalah:
1. Fitur yang digunakan untuk klasifikasi stress adalah dengan menggunakan fitur dari domain Heart Rate Statistical, yaitu Mean Heart Rate, Median Heart Rate, Mean Absolute Deviation Heart Rate dan Standard Deviation Heart Rate.

2. Data uji diambil dengan menggunakan $\mathrm{Mi}$ Band 2 yang dihubungkan melalui Bluetooth dengan aplikasi berbasis Android yang telah dikembangkan.

3. Nilai akurasi perbandingan antara hasil klasifikasi dan kondisi real responden mampu mencapai 58,3\% menurut Tabel 5.

Tabel 5 Perbandingan Hasil Klasifikasi dengan Kondisi Real

\begin{tabular}{cccc}
\hline No & Hasil & Kondisi Real & Kecocokan \\
\hline 1 & Stres Ringan & Stres Ringan & Cocok \\
2 & Stres Berat & Stres Berat & Cocok \\
3 & Stres Ringan & Stres Berat & Tidak Cocok \\
4 & Stres Ringan & Stres Ringan & Cocok \\
5 & Stres Ringan & Stres Sedang & Tidak Cocok \\
6 & Stres Ringan & Stres Sedang & Tidak Cocok \\
7 & Stres Ringan & Stres Ringan & Cocok \\
8 & Stres Ringan & Stres Ringan & Cocok \\
9 & Stres Sedang & Stres Sedang & Cocok \\
10 & Stres Berat & Stres Ringan & Tidak Cocok \\
11 & Stres Ringan & Stres Ringan & Cocok \\
12 & Stres Ringan & Stres Sedang & Tidak Cocok \\
\hline
\end{tabular}

\section{DAFTAR PUSTAKA}

BEN SALEM, Y. AND NASRI, S. (2009) 'Automatic classification of woven fabrics using multi-class support vector machine', Research Journal of Textile and Apparel. Emerald Group Publishing Limited, 13(2), pp. 28-36.

CLARK, R.C. AND MAYER, R.E., 2011. Elearning and The Science of Instruction: Proven Guidelines for Consumers and Designers of Multimedia Learning. John Willey \& Son.

CANNATARO, M., CUZZOCREA, A., MASTROIANNI, C., Ortale, R., Pugliese, A.: Modeling adaptive hypermedia with an objectoriented approach and XML. In: Presented at the 2nd International Workshop on Web Dynamics (WebDyn 2002) in Conjunction with the 11th International World Wide Web Conference (WWW 2002), Honolulu, Hawaii (2002)

DHUPIA, B. ABDALLA ALAMEEN, 2019, Adaptive eLearning System: Conceptual Framework for Personalized Study Environment. Advanced Informatics for Computing Research (pp.334-342)

IMADUDDIN, ZAKI, ABIDZAR T., HILMY, 2015.

Thesis Project: Aplikasi Mobile untuk Deteksi dan Klasifikasi Daun Secara Real Time. Depok : Sekolah Tinggi Teknologi Terpadu Nurul 
768 Jurnal Teknologi Informasi dan Ilmu Komputer (JTIIK), Vol. 8, No. 4, Agustus 2021, hlm. 763-768

Fikri.

KOLDIJK, S., SAPPELLI, M., VERBERNE, S., Neerincx, M.A. and Kraaij, W., 2014. The SWELL Knowledge Work Dataset for Stress and User Modeling Research Categories and Subject Descriptors. In: Proceedings of the 16th ACM International Conference on Multimodal Interaction (ICMI 2014). Istanbul.

SRIRAMPRAKASH, S., PRASANNA, V.D. AND MURTHY, O.V.R., 2017. Stress Detection in Working People. In: Procedia Computer Science. [online] Elsevier B.V.pp.359-366. Available at: <https://doi.org/10.1016/j.procs.2017.09.090>.

SHOFIA, RAHMI AMIRATUS, dkk. 2013. Penerapan

Metode Fuzzy K-Nearest Neighbor (FKNN) untuk Menentukan Kualitas Hasil Rendemen Tanaman Tebu. S1. Universitas Brawijaya Malang

VOGEL, S. AND SCHWABE, L., 2016. Learning and memory under stress: implications for the classroom. npj Science of Learning, 1(1), pp.110.

ZHENG, B., MYINT, S.W., THENKABAIL, P.S. AND AGGARWAL, R.M., 2015. A support vector machine to identify irrigated crop types using time-series Landsat NDVI data. International Journal of Applied Earth Observation and Geoinformation, [online] 34(1), pp.103-112. Available at: <http://dx.doi.org/10.1016/j.jag.2014.07.002>. 